интереса. Теле-суды - программы постановочные, но они подаются как реальные, жизнеподобные, именно этим они являют собой альтернативную театру и синематографу форму развлечения телеманов. По модели поединка выстроен судебный процесс «Модный приговор»: есть истец и ответчик, прокурор и адвокат, свидетели обвинения и защиты, независимый эксперт. Ведущий в роли судьи. Зрители в студии интерактивным голосованием выполняют функцию присяжных заседателей, которые выносят решение: во что одеть ответчицу (ответчика);

- «Кулинарный поединок» звезд. (Без комментариев);

- интерактивные голосования, споры, столкновение мнений «за» и «против» - повседневная форма вещания на радиостанции «Эхо Москвы». Ведущие изначально принимают установку на разделение мнений. В процессе выслушивания телефонных звонков (даются два номера телефона для интерактивного голосования - «за» и «против») слушатели открыто проговаривают всё, что считают нужным и что подчас мало кто осмелится говорить в прямом эфире. Станция сохраняет нейтралитет, но как бы то ни было, слово вылетело...

3. Третий вид игр - массовые состязания. Это разнообразные конкурсы, ответы на загадки, соревнования, выбор победителя путем интерактивного голосования. Это: «Евровидение», «Ледниковый период», «Большая опера» (2011, 2013), «Большой балет» (2012), «Большой джаз» (2013), «Битва хоров» (2012), «Битва экстрасенсов», «Голос» $(2012,2013)$, «Контрольная закупка» и многое другое.

Во всех трех игровых формах передач зритель вовлекается в участие. Ему дается право звонком по теле- фону и эсэмэсками влиять на результат или выражать свои симпатии.

Часто процесс застилает итоги, и ток-шоу заканчивается ничем: поговорили и разошлись, каждый остался при своем мнении. Итоги часто виртуальные: нельзя же отведать блюдо, приготовленное на экране в поединке той или иной звездой, чтобы определить победителя. Побеждает тот, чьи каламбуры смешнее или кто лучше спел...

Процессуальность, документальность, интерактивность, актуальные для современного искусства, обратились к массовому потребителю сильно адаптированными. За небольшим исключением, многие каналы СМИ оказываются, в скрытой или явной форме, развлекательными реалити-шоу: их задача, ради высокого рейтинга, - привлечь зрителей и заполнить время. Игровые схемы помогают обеспечить и то, и другое.

\section{Список литературы}

1. Фрай М. Коллективные действия // Макс Фрай. Арт-азбука [Электронный ресурс]. - Режим доступа: http://azbuka. gif.ru/alfabet/k/kollekt-deistviya/

2. Невский С. Революция как иронический жест // Трибуна современной музыки. - 2007. - № 2-3.

3. Хакимов T. Олег Кулик в проекте «Человек.док» [Электронный ресурс]. - Режим доступа: http://os.colta.ru/ mediathek/details/18927/

4. Катунян М. Новый тривий XX века: звук, число, обряд (А. Пярт, Л. Рубинштейн) // Миф. Музыка. Обряд. - М., 2007.

5. Катунян М. Структурные архетипы художественного текста // Музыкальное образование в контексте культуры: вопросы теории, истории и методологии. - М.: РАМ, 2009.

6. Катунян М. «Ночь в Галиции»: обряд, игра, перформанс // Ночь: Ритуалы, искусство, развлечение / ред.-сост. Е.В. ДуКОВ. - М.: ЛЕНАНД, 2009.

\title{
А.А. ДЕНИКИН
}

\section{В ЗАЩИТУ ВИДЕОИГР}

Проведя сопоставление научных работ ряда отечественных и зарубежных исследователей феномена видеоигр, автор обобщает выводы из работ ведущих западных специалистов в области исследования видеоигр, представляя взгляд на видеоигры как на особые интерактивные, эмерджентные социально-коммуникативные средства современной цифровой культуры, способствующие процессам обучения, развитию способности к целеполаганию и иных способностей геймеров.

Ключевые слова: видеоигра, исследования видеоигр, людология, интерактивность, иммерсивность, ситуативность, эмерджентность.

B странах Западной Европы и в США исследования феномена игр (англ. game studies) более десяти лет признаны самостоятельной дисциплиной. В то время как в России исследования видеоигр в качестве современной формы коммуникации и творчества единичны и нередко наследуют ряд сложностей и проблемных зон, которые западной гуманитарной наукой уже преодолены. Речь идет прежде всего о попытках некоторых отечественных исследователей применять привычную методологию академических гуманитарных наук при анализе феноме- 
на видеоигр. Как будет показано далее, такие «традиционалистские интервенции» в оригинальную область современной цифровой культуры с ее специфическими коммуникативно-выразительными формами оказываются не всегда уместными и нередко ведут к возникновению спорных гипотез и ошибочных выводов.

Под термином видеоигра (от англ. video game) понимается программное обеспечение, работающее на специальном оборудовании (компьютере, игровой консоли, портативном электронном аппарате), служащее для организации игрового процесса (геймплея), связи с партнерами по игре или само выступающее в качестве партнера. Данный термин трактуется расширенно, охватывая при этом как консольные, аркадные, портативные, так и компьютерные игры.

В качестве аудиовизуального средства коммуникации видеоигра задействует элементы повествования, изображения и анимацию, видеозаставки (кат-сцены), текст на экране, титры, движение камеры обзора и другие визуальные и звуковые приемы выразительности, что сближает игры с кинематографом, телевизионными программами. Вместе с тем видеоигры обладают и специфическими возможностями, такими как интерактивность, интерфейс, навигация по игровому пространству, алгоритмическое и процедурное взаимодействие между игрой и пользователем и прочее.

Американский исследователь М. Вульф (M.J.P. Wolf) отмечает: «Восприятие игры отличается от того, как воспринимаются другие медиа. Вероятно, можно определить просмотр кинофильма как "активный" процесс, направленный на внимание к тому, что показывается, включающий воображение и процесс мышления для того, чтобы понять, “прочитать” фильм. Но видеоигры требуют от игрока большего - физического действия, ввода данных для того, чтобы игра функционировала, и часто эти пользовательские реакции лимитированы во времени» [1, p. 23].

Западные исследователи Э. Аарсет (E. Aarseth), М. Эскелинен (M. Eskelinen), Х. Ловуд (H. Lowood), Дж. Джуул (J. Juul) и другие не раз отмечали различия между видеоиграми и иными, более традиционными медиа технологиями и коммуникациями и утверждали при этом, что для понимания специфики видеоигр необходимо вырабатывать особые методы и критерии оценки, отличные от методологий, принятых в исследованиях академических дисциплин. Данные авторы пытались препятствовать попыткам ассимиляции изучения видеоигр в теории нарративных медиа, а также утверждали недопустимость «визуализма» в исследованиях видеоигр, который, по их мнению, проявляется в некорректных попытках некоторых ученых исследовать видеоигры в категориях кинематографической теории.

Один из ведущих людологов ${ }^{1}$ М. Эскелинен писал: «К счастью, геймеры, не отягощенные теорией, прекрасно

\footnotetext{
1 Людология (англ. ludology - игроведение) - раздел научного знания, посвященный аспектам, связанным с созданием и анализом игр.
}

разбираются, в чем различие между повествованием на экране и действиями в процессе игры: ведь если я кидаю вам мяч, очевидно, что я ожидаю, чтобы вы бросили мне его обратно, а не начинали рассказывать какие-то истории» [2].

Пожалуй, наиболее авторитетный людолог Э. Аарсет - редактор он-лайн журнала Game Studies - неоднократно подчеркивал бесперспективность «колонизации» новой сферы исследований видеоигровой формы академическими теориями. «Наибольшая опасность для исследования игр без преувеличения исходит от академической среды, - писал Аарсет. - Чтобы создать что-то новое, обычно приходится теснить старое, и все традиционное быстро реагирует на эти попытки, пытаясь представить новое как “хорошо забытое старое". Игры это не разновидность кино или литературы, но попытки “колонизовать" игры литературными и киноведческими теориями уже предпринимались и, без сомнения, еще будут предприниматься» [3].

Работы ряда российских исследователей видеоигр, опубликованные до сих пор, как раз отличаются стремлением авторов перенести отработанные и общепринятые академические искусствоведческие, культурологические и психологические теории на методику исследования видеоигровых практик.

Так, например, в своей диссертационной работе, защищенной в 2008 году в Санкт-Петербургском государственном университете профсоюзов, И.И. Югай рассматривает коммерческие игры (например, такие, как Мах Payne, The Chronicles of Riddick и др.) как «жанр художественного творчества» и как «явление художественной культуры», так как они, по его мнению, «отвечают всем основным требованиям художественного произведения (образность, антропоцентризм, целостность, диалогичность, эмоциональность, экспрессивность, символичность, наличие образа автора)» [4, с. 3].

Используя кинематографическую терминологию, И.И. Югай в качестве наиболее значимых видеоигровых «художественных» приемов указывает на «выразительность движения интерактивной виртуальной камеры, выражающее состояние персонажа; наделение виртуальных предметов особым смысловым значением; использование пространственных характеристик виртуального места действия для темпоритмической организации драматургического действия; изменение освещения, характеристик текстур, формы объектов» [4, с. 14]. Проводя параллели между театральным искусством и видеоиграми, Югай считает, что в моменты геймплея «иммерсионный эффект сравним с эффектом перевоплощения в игре актера», а «в хорошо продуманной игре зритель может пережить воплощение в этого персонажа» $[4$, с. 14,18$]$.

Используя методологию советского искусствознания (ссылаясь при этом на М.С. Кагана, И.А. Кравченко, А.Я. Флиера и др.), автор диссертации определяет, что «основная отличительная особенность (компьютерной игры. - А.Д.) как художественного произведения - ее 
диалоговая (интерактивная) форма» [4, с. 23]. Специфику видеоигр Югай видит в «мысленном общении зрителя с художественными образами и интерпретации произведения», которые «продолжаются в компьютерной игре виртуальным взаимодействием с персонажами и предметами игрового мира» [4, с. 24].

Следуя тенденции, проявившейся у И.И. Югай, Н.А. Мошков в своей диссертационной работе «Художественно-выразительные средства компьютерных игр: типология и эволюция» (2011) дает анализ особенностей системы художественно-выразительных средств и приемов, используемых в видеоиграх «для создания художественного образа». По мнению Мошкова, компьютерные игры «открывают новую сферу эстетической активности, выступая в качестве инновационной формы выражения и познания эмоций через художественный образ и его смысловое наполнение» [5, с. 13].

Продолжая рассуждать в терминах кинематографической выразительности, Мошков заявляет: «В интерактивных участках (видеоигры. - А.Д.) пространственно-временное и изобразительно-пластическое решение формируется при помощи длительных планов и внутрикадрового монтажа <...> Для создания эмоционально-эстетического воздействия автор организует внутриигровое пространство, используя свет, звук, жесты персонажей и т. д. Художественной единицей становится мизансцена, используемая для организации предметного пространства» [5, с. 17].

На основе приведенных в работе доводов диссертант приходит к выводу о том, что «в компьютерных играх скриптовая сцена является главной повествовательной единицей художественно-образного и смыслового развития произведения, поскольку каждый ее кадр передает значение. Именно скриптовые сцены позволяют раскрыть драматургию истории посредством организации единства художественных средств и их преподнесения в необходимом ключе» [5, с. 18].

Как будет показано далее, подобные рассуждения свидетельствуют о непонимании указанными авторами специфики видеоигровой выразительности, они не владеют специальной видеоигровой терминологией, что, по всей видимости, обусловлено слабым знакомством авторов с западными исследованиями видеоигр.

Ряд других отечественных исследователей, основываясь на теориях академической психологии, видят в видеоиграх серьезную опасность как для физического, так и психического здоровья человека. Так, А.Е. Войскунский [6], М.С. Иванов [7] и другие отмечают возникновение тенденции виртуальной аддикции, предпосылками для которой может послужить существующая и все более уверенно овладевающая сознанием геймеров психологическая зависимость от компьютерных игр, которая ведет к деформации и дегуманизации личности, прогрессивному отчуждению людей, потере коммуникабельности, росту агрессивности, асоциальному поведению.

Рассмотрев исследования западных специалистов, можно показать неточность подобных суждений и выво- дов, поскольку видеоигры, напротив, являются культурно-эстетическим, содержательным коммуникационным средством, средством социализации, обучения и развития способностей геймеров.

В своем программном исследовании «Cybertext: Perspectives on Ergodic Literature» Э. Аарсет утверждает что практики герменевтической интерпретации текста не всякий раз полностью применимы к видеоиграм. «Интерпретация письменного текста всегда происходит в голове у зрителя, - пишет Аарсет, - в то время как пользователь кибертекста управляет текстом не только ментально» [8, р. 1].

Другими словами, когда читатель читает роман, он осознает новые смыслы, интерпретируя текст. Когда же геймер играет в видеоигру, он создает новые «тексты», трансформируя виртуальный мир и объекты на экране. Поэтому вовсе не катарсис делает игры серий «The Elder Scrolls» (1994-2012) или «Grand Theft Auto» (19972013) привлекательными для игроков, а возможность для геймера выйти за пределы предзаданного сюжета и исследовать виртуальные миры по-своему. В литературе и кинематографе тот опыт, который может испытать зритель, определяют автор, сценарист или режиссер; в играх геймер конструирует свой собственный опыт, который совершенно не обязательно связан с повествованием.

Исследователь и гейм-дизайнер Г. Фраска (G. Frasca) проводит разделительную черту между повествованием как структурно выстроенной последовательностью событий и симуляцией, контролируемой игровыми правилами, которые геймер должен учитывать, тем самым определяя последовательность игровых событий. Для Фраски задача гейм-дизайнера - быть не рассказчиком, а, скорее, ведущим в игре, тем, кто контролирует выполнение игровых правил, а не сообщает какие-то сочиненные заранее рассказы [9, р. 232].

Исследователь М. Пикард (M. Picard) справедливо замечает: «Видеоигры основаны на игровых правилах и интерактивности, что делает их отличными от традиционных искусств, таких как кинематограф или театр, и требует особых методов анализа. Эстетика видеоигр не ограничивается тем, как игра выглядит или как звучит, но связана с тем, как она играется. Геймплей <...> не связан с теми эстетическими принципами, с которыми обычно ассоциируются традиционные виды искусств» $[10$, p. 334]. В этом смысле представляется спорной попытка И.И. Югай представить видеоигры как типичный «жанр художественного творчества» и как «явление художественной культуры».

Среди разнообразия жанров и разновидностей игр имеются те, которые в значительной мере отражают риторику художника, создателя, дизайнера-разработчика. Такие видеоигры рассматривают в своих книгах М. Флэнеган (M. Flanagan) [11] и Я. Богост (I.Bogost) [12]. Однако большая часть коммерческих популярных видеоигр, являясь социальными артефактами, исследуются как нечто большее, нежели «жанр художественного творчества», и более широкое, чем «явление художественной культуры». 
М. Вульф предостерегает от рассмотрения особенностей видеоигр в контексте их иконографии. Визуальные элементы видеоигр могут быть различными при том, что сами игры будут весьма похожими. Вульф считает, что специфика игры не в иконографии, а в особенностях интерактивности [13, р. 114-117].

В статье «Genre Trouble» Э. Аарсет утверждает, что репрезентативные аспекты игры, например внешний вид (аватар) персонажа Лары Крофт в одноименной видеоигре, имеют малое влияние на процесс игры (геймплей). «Удовольствие от геймплея <...> не в визуальной составляющей игры, а в кинестетике, функциональности и познавательности. Ваши навыки будут вознаграждены, ваши ошибки наказываются в буквальном смысле. Игра "видится" не так, как видится кино» [14, р. 45]. Разработчик и исследователь видеоигр Питер Дуглас Молиньё (P. Molyneux) считает, что геймер - «это лучший видеооператор, потому что он всегда знает, что ему хотелось бы увидеть <...> следует дать геймеру возможность самому свободно выбирать ракурс и план просмотра» [15, р. 54].

Видный американский культуролог А. Гэлоуэй (A. Galloway) объясняет принципиальную разницу между киноизображением и видеоигровым изображением: «Видеоигровое изображение требует полностью смоделированного пространства для действия. Традиционное кинематографическое изображение практически никогда не подразумевает воссоздания полноценного пространства. Художники и декораторы воссоздают для кинофильма только часть сцены, которая попадет в кадр. <...> Позиция камеры обзора во многих видеоиграх ничем не ограничена. Игрок может самостоятельно управлять направлением камеры» [16, р. 63-64]. Таким образом, утверждения Н.А. Мошкова о том, что «в интерактивных участках (видеоигры. - А.Д.) пространственно-временное и изобразительно-пластическое решение формируется при помощи длительных планов и внутрикадрового монтажа» [5, с. 17], оказываются мифом.

Очевидно, что в отношении открытого пространства видеоигры, не ограниченного рамкой операторской кинематографической камеры, не применимо понятие мизансцены. Мизансцена (франц. mise en scène - размещение на сцене) как расположение актеров на сцене в тот или иной момент спектакля, экранного действия не приемлема в отношении видеоигр. Мизансцена - это всегда ограниченное, выверенное художником пространство. Пространство в современных видеоиграх открыто трансформациям и изменениям, полностью не подконтрольно художнику. Это не ограниченное рамками сцены (или кадра) игровое пространство функционирует не по воле художника, а в соответствии с игровой программой, с алгоритмами вариативности (рандомизации) и при непосредственном воздействии игроков на объекты в этом пространстве. Такое пространство имеет мало общего с мизансценированием в художественных произведениях. Мизансцена не может считаться основной «художественной единицей», используемой «для организации предметного пространства виртуальной реальности» [5, c. 17]. Как и скриптовая сцена не может быть главной повествовательной единицей художественно-образного и смыслового развития видеоигр.

Выделенные И.И. Югай «художественные средства» видеоигр, такие как «выразительность движения интерактивной виртуальной камеры, выражающее состояние персонажа»; «наделение виртуальных предметов особым смысловым значением»; «изменение освещения, характеристик текстур, формы объектов» [4, с. 14], не только не становятся основополагающими для геймплея, но выполняют, скорее, «декоративную», прикладную функцию технико-предметного оформления и интерфейса в процессе навигации геймера по игровому миру.

Что касается имерсионного эффекта, обнаруженного Югай в видеоиграх, то, вероятно, исследовательнице следовало бы сначала разобраться с игровой терминологией. Согласно словарю, иммерсионный метод наблюдения (в оптической микроскопии) - это введение жидкости между объективом микроскопа и рассматриваемым предметом для усиления яркости и расширения пределов увеличения изображения [17]. Судя по всему, И.И. Югай имела в виду «иммерсивный» (от англ. immersive - иммерсивный, всеобъемлющий, с полным погружением) - совершенно иное понятие, означающее погружение в смоделированную псевдореальность, отсутствие критической дистанции между искусственным пространством и реципиентом.

Й. Дови (J. Dovey) и Х. Кеннеди (H.W. Kennedy) пишут: «Текстуальный анализ, основанный на исследовании означающего и означаемого, был признан неадекватным для понимания различия между участием геймера в видеоигровом пространстве в качестве персонажа/аватара и представлением персонажей на обычном киноэкране <...> что сделало концепцию подражания герою и сопереживания в целом неуместной. Если персонаж представляет собой, например, фигуру на шахматной доске, вряд ли кто-то согласится идентифицировать себя с ней. В игре “внутренняя жизнь" персонажа малозначима, и все зависит от внешних действий игрока; персонаж игрока на экране должен выполнять игровые задачи, а не думать о них» [18, р. 96]. По мнению М.Л. Райн (M.-L. Ryan), «влияние игрового персонажа на сюжет игры не в его выразительном поведении, а, скорее, в том, как при помощи персонажа игрок исследует мир, решает игровые задачи, выполняет действия, сражается против врагов» [19]. Как справедливо замечают Дж. Кинг (G. King) и Т. Крживинска (T. Krzywinska), «играть в шутер от первого лица вовсе не означает вживаться в роль стрелка. Это означает играть, используя эту роль, что совершенно иное, нежели вживаться в роль» [20, р. 201].

Таким образом, версия И.И. Югай о том, что в видеоиграх «иммерсионный эффект сравним с эффектом перевоплощения в игре актера», а «в хорошо продуманной игре зритель может пережить воплощение в этого персонажа» $[4$, с. 14, 18], не состоятельна по причине своей абсурдности. Игроки «со стажем» знают, что отыгрывание геймером роли в многопользовательских он-лайн играх означает не полное перевоплощение в «другого», а кон- 
венциональное «перенесение» себя в рамки ограничений (или, напротив, необычных возможностей), свойственных «другому». Если бы И.И. Югай имела опыт участия в ролевых играх, она бы знала, что какую бы роль игрок ни отыгрывал, в той или иной степени сохраняется критическая дистанция по отношению к своему персонажу. Эта дистанция - пространство для воображения и импровизации - своего рода движущая сила интереса геймеров к ролевым играм. Актер перевоплощается, чтобы играть; геймер играет роль, чтобы действовать, а не изображать действие. Актер играет так, как он представляет себе образ кого-то, геймер «играет» себя, приняв и соблюдая реальные возможности и ограничения, свойственные выбранной роли. Югай считает, что «основная отличительная особенность компьютерной игры как художественного произведения - ее диалоговая (интерактивная) форма» [4, с. 23].

Метафора «диалога» стала общепринятой в академической культурологической теории (например, «диалогизм» в трудах В. Эбнера, М. Бубера, М. Бахтина и др.). Однако большинство западных исследователей видеоигр считают, что интерактивность и диалог (как равноправное общение между автором и аудиторией) - несколько разные вещи.

Как показывают исследования Й. Дови и Х. Кеннеди, «интерпретация продуктов традиционных медиа (кино, литературы, ТВ) отличается от того процесса, когда мы материально трансформируем текст, заставляя его выглядеть и звучать по-новому; понимание интерактивности ближе к вопросам машинно-компьютерных интерфейсов и дизайна» [18, p. 6].

В книге «Cybertext: Perspectives on Ergodic Literature» Э. Аарсет исследует концепт «кибертекст» как средство обратной связи между читателем и текстом и предлагает концепт «эргодический текст» (аналог интерактивности) как средство механической перестройки текстовой структуры читателем (геймером). Интерактивность видеоигр в понимании Э. Аарсета заключается в возможности производить текст путем физической трансформации текстовых структур, а не в опыте интерпретаций или рефлексий по поводу текста. Такая смена интерпретационной стратегии от диалогичного общения читателя и автора посредством текста к физической интервенции геймера в интерактивное игровое пространство стала важнейшей темой обсуждения в исследованиях видеоигр в США и странах Западной Европы.

Эту же идею развивает Т. Фридман (T. Friedman), обсуждая игру Sid Meier's Civilization II (1996). В отличие от реальных бытовых игр, где правила могут быть изменены по договоренности играющих, в видеоиграх правила закреплены программным кодом. Фиксированный программный алгоритм не дает возможности нарушать правила (исключение - взлом алгоритма, хакинг). Это, по мнению Фридмана, обусловливает возможность передачи идеологических посланий, которые должны быть усвоены игроками для того, чтобы выигрывать или успешно выполнять игровые задачи [21].
Уточняя мысль Т. Фридмана, американский культуролог и философ Я. Богост утверждает, что геймеры имеют дело с двумя видами коммуникации: «эргодическое (интерактивное) прохождение и традиционный интерпретативный тип - оба способствуют полноценному удовольствию при возможности осмысления игры. Взаимоотношения и связь между этими режимами крайне важны для понимания видеоигрового опыта» [22, p. 14].

В таком контексте крайне неадекватной выглядит идея И.И. Югай о «мысленном общении зрителя с художественными образами и интерпретации произведения», которые «продолжаются в компьютерной игре виртуальным взаимодействием с персонажами и предметами игрового мира» [4, с. 24].

Подобные «интерпретационные стратегии» уже пыталась применять американская исследовательница Дж. Мюррей (J. Murray), утверждая, что «любая игра, электронная или обычная, может переживаться как символическая драма. <...> В игре “Тетрис" как только вы успешно выполняете действия, результат пропадает с экрана. Играть успешно значит одно - непрерывно быть включенным в поток действий. Это отличная аллегория того, как мы, рядовые американцы, живем в 1990-е годы, постоянно бомбардируемые заботами, которые требуют нашего внимания, аллегория того, как мы вынуждены решать проблемы только ради готовности к их следующему натиску» [23].

Такая интерпретация «Тетриса» вызвала жесткую критику людологов в лице, например, М. Эскелинена. Он возражал: «В абстрактных играх, таких как "Тетрис", имеются условия, объекты и события, но нет персонажей. Кроме того, есть события, изменяющие обстоятельства игры, но не передающие или сообщающие истории <...> Вместо того, чтобы изучать саму игру, Мюррей пытается интерпретировать ее внешний вид или, хуже того, подменять саму игру своими мыслями о ней; таким образом мы ничего не поймем из того, что делает эту игру “Тетрисом". Цель этого интерпретационного насилия пугающая: желание найти или сфабриковать историю любой ценой» [2].

Очевидно, что М. Эскелинен слишком категоричен, утверждая, что видеоигры могут изучаться исключительно в категориях, которые делают игры играми, а это правила, игровые материалы, события, составляющие гейплей, и пр. Многие игры используют повествовательные сюжеты (например, The Elder Scrolls IV: Oblivion, 2006; Grim Fandango,1998 и др.), и игроки получают большое удовольствие, управляя развитием историй. Однако «драматургичность» этих историй, если такое слово можно применить к играм, не в «глубоких смыслах», заложенных автором и интерпретируемых геймером, а в ситуативных взаимодействиях, в актуализации настоящего мгновения и ощущении геймером своей способности действовать и чувствовать одновременно в процессе игры.

Как заключают Й. Дови и Х. Кеннеди, «смыслы, генерируемые игрой, отличаются от смыслов, складывающихся при чтении. Читать - значит мысленно интерпретировать текст. Играть - генерировать смыслы в процессе игрь 
<...> Это не говорит о том, что репрезентация и значения вовсе не важны. Игроки, несомненно, интерпретируют события, происходящие в игре, их действия с игрой осмыслены. Тем не менее, игрок получает меньшее удовольствие от интерпретации в игре по сравнению с романами или кино» [18, р. 101].

Из сказанного очевидно, что вопреки надеждам И.И. Югай и Н.А. Мошкова смысл игровой деятельности и удовольствие от нее заключаются вовсе не в том, чтобы «раскрыть драматургию истории посредством организации единства художественных средств и их преподнесения в необходимом ключе» [5, с. 18], а в различных режимах «материального», социального и ситуативного взаимодействия между геймером, видеоигровым алгоритмом и социальным окружением, формирующимся вокруг видеоигрового продукта.

Появление таких многопользовательских игр, как WOW (2004), Ultima online (1996), Star Wars: Knights of the Old Republic (2003) и пр., опровергает идею о том, что игра - это всегда замкнутая в себе, отграниченная от социальных процессов «свободная» деятельность (см. работы Й. Хёйзинги, Р. Каюа).

Датский культуролог К. Джессен (C. Jessen) считает, что видеоигры обретают свои смыслы и значимость в непосредственном опыте их использования, в конкретных ситуациях. В этом отношении игры предстают, скорее, современной социокультурной практикой, нежели средством передачи сообщений и смыслов от автора зрителю. «Невозможно интерпретировать смысл игры вне конкретной практики игры, которая сама по себе есть путь к ее пониманию. Например, то, что может само по себе выглядеть чрезвычайным насилием на экране, на практике способно иметь совершенно иную функцию. Игроки могут, например, стрелять друг в друга в агрессивной игре “Doom 2" и при этом незатейливо общаться как лучшие друзья, что обычно в случае жанра военных игр» [24].

Таким образом, не только невозможно понять игру вне опыта игры, но и сама игра - только часть настоящего опыта геймера. Смысл игр не заключен в самой игре, а выражается через нее. Процесс генерации смыслов осуществляется как в виртуальном игровом мире, так и в реальном мире социальных взаимодействий. Геймеры участвуют в он-лайн форумах, посвященных любимой игре, становятся членами игрового клана или организации, пишут собственные гайды по прохождению сложных уровней игры, обмениваются мнениями на форумах и ведут собственные блоги. Эта продуктивная деятельность подтверждает связь игр с массовой популярной культурой и дистанцирует видеоигры от классической парадигмы творчества, построенной на противопоставлении «автор - публика». Современные коммуникационные технологии способствуют развитию иной парадигмы, представляющей гейм-дизайнера в качестве инициатора открытого коммуникативного поля, в котором осуществляется креативное взаимодействие игроков.
Бессмысленно играть в многопользовательскую игру World of Warcraft (2004) вне социализации в игровом комьюнити. 90 уровней, предложенных в игре, можно достичь достаточно быстро. Но настоящее удовольствие, смысл игры можно обнаружить, только когда твоя игра превращается в нечто большее, нежели «игра для себя», когда она становится игрой «для других и для себя», геймер оказывается частью игрового клана, гильдии, социальной группы, находит друзей и врагов, когда он чувствует, что занят чем-то важным для других, чем-то, что больше него самого.

Смысл игры в Counter-Strike заключен вовсе не в графике, «драматургии» сюжета или возможности выплеснуть свою агрессию, но в социализации и объединении нескольких игроков в процессе выполнения общего дела. Смыслы создаются в ходе активного общения и взаимодействия между игроками внутри специфических игровых контекстов.

Поэтому смыслы видеоигр ситуативны и социально обусловлены. Они генерируются в результате взаимодействия игроков и не предзаданы игровыми программами, правилами, игровой формой, сюжетом, выразительными средствами или техническими устройствами самими по себе. Смыслы игр складываются в процессе активной творческой переработки и исследования игрового контента группами игроков, рецензентов, критиков, фанатов.

Даже такие «повествовательные» игры как Max Payne, The Chronicles of Riddick представляют собой социальнокоммуникативные, а не сугубо художественные формы, так как формируют вокруг себя группы фанатов, продуктивно взаимодействующих друг с другом на сайтах, форумах и специальных сборах. Эта активность приводит к тому, что разработчики усовершенствуют указанные игры в соответствии с предложениями, сформулированными геймерами и фанатами.

В исследовании «Rules of Play» К. Сален и Э. Зиммерман (K. Salen, E. Zimmerman) описывают процесс создания видеоигр: дизайнер определяет контекст, в котором происходит взаимодействие игроков, в результате чего возникают смыслы. «Для гейм-дизайнера придумывание смыслов - второстепенная задача, - пишут авторы. Гейм-дизайнер создает непосредственно структуру правил и лишь опосредованно влияет на опыт игры, когда правила игры учитываются игроками. Так как игра разворачивается в процессе, трансформируется в процессе, могут происходить неожиданные вещи, которые невозможно полностью предсказать. Поэтому дизайн - не создание фиксированных объектов. Это создание набора возможностей» [25, р. 28-29].

Современные видеоигры обладают комплексными социокультурными эмерджентными свойствами ${ }^{2}$ с не-

\footnotetext{
2 Понятие «эмерджентные свойства» (англ. emergent properties) было сформулировано Т. Парсонсом в рамках его анализа социальных систем и критики редукционизма. 0но основано на трех связанных между собой идеях. (1) Социальные системы обладают структурой, которая возникает (emerges) в процессе социального взаимодействия. (2) Эти эмерджентные, то есть возникающие свойства, не могут быть сведены
} 
фиксируемыми, динамически изменяемыми контекстами и смыслами, складывающимися и разрушающимися в процессе игры. Сюжетные и повествовательные возможности современных видеоигр, несомненно, важны как для разработчиков, так и для геймеров. Однако, как и игровые визуальные образы, видеоизображения, звук, игровой нарратив выполняет функцию контекста для взаимодействия пользователей и, вопреки выводам некоторых отечественных исследователей, не может определять смысл и специфику видеоигр в целом. Неудивительно, что, рассматривая видеоигры в связи с их повествовательными возможностями, такие исследователи приходят к неизбежным противоречиям: показывая в своих работах, что видеоигры очевидно «уступают» литературе и кинематографу по своим нарративным качествам, эти авторы вынуждены все равно признавать видеоигры «жанром художественного творчества» и «явлением художественной культуры».

В появлении нового поколения практиков и исследователей видеоигр как уникальной и самостоятельной формы коммуникаций XXI века видится будущее электронных игр. Видеоигры созданы для того, чтобы быть интерактивными, эмерджентными соцально-коммуникативными системами, способствующими процессам обучения, получению удовольствия, развитию способности к целеполаганию и условий для самореализации человека.

\section{Список литературы}

1. Wolf M. The Video Game Explosion: a History from Pong to Playstation and beyond / M. Wolf (ed.). - Westport, Connecticut, London: Greenwood Press, 2008.

2. Eskelinen M. The Gaming Situation // Game Studies 1.1, July, 2001 [Электронный ресурс]. - Режим доступа: www. gamestudies.org/0101/eskelinen/

3. Aarseth E. Computer Game Studies, Year One // Game Studies, 2001 [Электронный ресурс]. - Режим доступа: http.//www. gamestudies.org/0101/editorial.html

4. Югай И.И. Компьютерная игра как жанр художественного творчества на рубеже XX-XXI веков: дис. ... канд. искусствоведения, 2008 [Электронный ресурс]. - Режим доступа: http://www.gup.ru/uni/science/aspirant/aref/ arefugay.doc

5. Мошков Н.А. Художественно-выразительные средства компьютерных игр: типология и эволюция: дис. ... канд. искусствоведения, 2011 [Электронный ресурс]. - Режим доступа: http://www.gup.ru/uni/science/aspirant/council/ moshkov_avtoreferat.doc

6. Войскунский А.Е. Феномен зависимости от Интерне$m a$ // Гуманитарные исследования в Интернете / под ред. А.Е. Войскунского. - М., 2000.
7. Иванов М.С. Психологические аспекты негативного влияния игровой компьютерной зависимости на личность человека // Психологический журнал. - 1999. - Т. 20.

8. Aarseth E. Cybertext: Perspectives on Ergodic Literature. Baltimore: Johns Hopkins University Press, 1997 [Электронный ресурс]. - Режим доступа: http://www.autzones.com/ din6000/textes/semaine09/Aarseth(1997).pdf

9. Frasca G. Simulation Versus Narrative: Introduction to Ludology //The Video Game T. Reader, M. Wolf, B. Perron (ed.). - New York: Routledge, 2003.

10. Picard M. Art and Aesthetics//The Video Game Theory Reader 2, B. Perron, M. Wolf (ed). - New York; London, 2009.

11. Flanagan M. Critical Play: Radical Game Design. Massachusetts: Massachusetts Institute of Technology, 2009.

12. Bogost I. Persuasive Games: the Expressive Power of Videogames. - Massachusetts: Massachusetts Institute of Technology, 2007.

13. Wolf M. (ed). The Medium of the Video Game. - Austin: University of Texas Press, 2001.

14. Aarseth E. Genre Trouble // N. Wardrip-Fruin, P. Harrigan (eds.). First person. - Cambridge, Mass.: MIT Press., 2004.

15. Molyneux P. The Future of Games // MIT Program in Comparative and Media Studies, Computer and Video Games Come of Age // Videogames and education. H. Brown. - New York, London: M.E. Sharpe, Inc., 2008.

16. Galloway A. Gaming: Essays on Algorithmic Culture. Minneapolis: University of Minnesota Press, 2006.

17. Физическая энциклопедия: в 5 т. - М.: Советская энциклопедия, 1988.

18. Dovey J., Kennedy H. W. Game Cultures. Computer Games as New Media. - New York: Open University Press, 2006.

19. Ryan M.-L. Beyond Myth and Metaphor: The Case of Narrative in Digital Media, Game Studies, 1(1) [Электронный ресурс]. - Режим доступа: www.gamestudies.org/0101/

20. King G., Krzywinska T. Tomb Raiders and Space Invaders: Videogame Forms and Contexts. - London: I.B. Tauris, 2006.

21. Friedman $T$. Civilization and its Discontents: Simulation, Subjectivity, and Space // G. M. Smith (ed.). On a Silver Platter: CD-ROMs and the Promise of a New Technology. New York: University Press, 1999.

22. Bogost I. Unit Operations: An Approach to Videogame Criticism. - Cambridge, MA: MIT Press, 2006.

23. Murray J. Hamlet on the Holodeck: The Future of Narrative in Cyberspace. - Cambridge, MA: MIT Press, 1997.

24. Jessen C. Interpretive Communities: the Reception of Computer Games by Children and the Young, 1998 [Электронный ресурс]. - Режим доступа: http://www.carsten-jessen. $\mathrm{dk} /$ intercom.html

25. Salen K., Zimmerman E. Rules of Play. Game Design Fundamentals. - Massachusetts: MIT Press, 2004.

26. Аберкромби Н., Хилл С., Тернер Б. Социологический словарь. 2-е изд., перераб. и доп. / пер. с англ. И.Г. Ясавеева под ред. С.А. Ерофеева. - М.: ЗАО «Экономика», 2004.

\footnotetext{
к биологическим или психологическим характеристикам социальных деятелей - например, культуру невозможно объяснить, обращаясь к биологии. (3) Смысл социального действия нельзя понять в отрыве от общего контекста социальной системы, в рамках которой оно происходит. Таким образом, все социальные объекты обладают эмерджентными свойствами, которые не могут быть сведены к какому-либо одному фактору [26, с. 304].
} 